\title{
Stability Study of Eugenol and Kitolod Extract (Isotoma Longiflora) Nanoemulsion Concentrate for Botanical Pesticide Application
}

\author{
Melati Septiyanti $^{1, *}$, Nur Fauziyah ${ }^{1}$, Rahmawati Putri ${ }^{2}$, Yenny Meliana ${ }^{1}$ \\ 1 Research Center for Chemistry, Kawasan Puspiptek Serpong, Gd.452, South Tangerang, Banten, 15314, Indonesia \\ 2 Research Center for Biomaterial, Jl. Raya Bogor Km.46, Cibinong, West Java, 16911, Indonesia \\ * Correspondence: mela003@lipi.go.id;
}

Received: 17.04.2020; Revised: 5.05.2020; Accepted: 8.05.2020; Published: 13.05.2020

\begin{abstract}
In the agricultural field it is common to use synthetic pesticide due to practical and efficient application yet it can leave residue in long term use that can be harmful to health, causing resistance and resurgence of pests and disturbing the balance of the ecosystem. Botanical pesticide is potential to substitute synthetic pesticide due to abundant raw materials in nature, the manufacturing process does not require high technology and easily biodegradable so it is relatively safe to use. The natural ingredients that can be used for botanical fungicide are eugenol and kitolod leaves because it has antimicrobial compound namely hexanedioic acid and silicic acid. This active agent was formulated in Emulsifiable Concentrate (EC) due to practical and economical factors. This study investigated the stability of nanoemulsion concentrate of eugenol and kitolod extract combination with variation of Span 85 and Tween 80 ratio with different hydrophile-lipophile balance (HLB) 5-7. The most stable formulation consists of $99 \%$ eugenol, 1\% kitolod extract, combination surfactant of Span $8560 \%$ and Tween $8040 \%$ and ethanol as solvent with ration 1:5. The average particle size is $288.7 \pm 9.2 \mathrm{~nm}$ with polydispersity index $0.339 \pm 0.055$.
\end{abstract}

Keywords: Botanical pesticide; antimicrobial; nanoemulsion; emulsifiable concentrate; stability.

(C) 2020 by the authors. This article is an open access article distributed under the terms and conditions of the Creative Commons Attribution (CC BY) license (https://creativecommons.org/licenses/by/4.0/).

\section{Introduction}

The use of a synthetic fungicide is considered practical and efficient, but long-term use has negative impacts such as leaving residues that are harmful to health, causing resistance and resurgence of pests and disturbing the balance of the ecosystem. The alternative to overcome these problems is using organic or botanical fungicide. Botanical fungicide has promising prospects such as abundant raw materials in nature, low toxicity and easily biodegradable so it is relatively safe to use [1].

One of the natural ingredients that has the potential to be used as a botanical fungicide is kitolod plant. Kitolod (Isotoma longiflora L.) is a plant that is empirically used as traditional medicine. Kitolod possesses secondary metabolites such as alkaloids, terpenoids, flavonoids, tannins and polyphenols which is active as antibacterial, antimicrobial and antiseptic, insecticide and antifungal [2].

The use of kitolod extract as an antifungal agent can be enhanced by combining with other compounds. The other active ingredient that is also widely used in botanical fungicide 
formulation is eugenol. Eugenol has pharmacological activities as analgesic, antiinflammatory, antimicrobial, antiviral, antifungal and antiseptic [3].

The type of formulation which is widely provided in botanical fungicide manufacture is Emulsifiable Concentrate (EC). EC formulation, is a liquid concentrated formulation contained active agent based on oil and water phase and if it mixed with water, it will form an emulsion. EC formulation is preferred because of its ease of manufacture and application. EC formulation uses water as solvent in field applications, making it very economical and easy to use [4].

An important step in making formulations is the process of mixing insoluble ingredients into formulations that are soluble, homogeneous and stable over a long period of time. Emulsifiers are needed as key ingredients to form emulsions and stabilize active agents in emulsified water or oil. The right combination of surfactants and co-surfactants is a substantial factor for the formation of stable emulsified $\mathrm{o} / \mathrm{w}$. The $\mathrm{o} / \mathrm{w}$ emulsion consists of oil droplets surrounded by a thin interface layer consisting of emulsifier molecules, dispersed in aqueous continuous phases [5]

Some literature mentions the potential of Kitolod plant and eugenol as active ingredients for pesticide application, but no comprehensive study has been carried out on the formulation stability in nanosized droplet. Thus, this study aimed to investigate the stability of nanoemulsion concentrate which consisted mixture of Kitolod extract and eugenol as active ingredients, span 85 and tween 80 as surfactant and ethanol as a solvent. The stability test was conducted for 6 hours with emulsion separation, particle size and polydispersity index characterization.

\section{Materials and Methods}

\subsection{Materials and Instruments.}

The materials are fresh kitolod leaves from Pangandaran, West Java, Indonesia, eugenol (USP, BPPT, Indonesia), Span 85 (Sigma Aldrich, USA), Tween 80 (Merck, Germany), ethanol absolute (Merck, Germany), distilled water.

The equipment to identify chemical constituent used Agilent 7890B Gas chromatography (GC) with HP 5977A Mass Selective Detector (MSD) and FTIR Shimadzu Prestige-21. Particle size and polydispersity index were conducted using Horiba Nano partica SZ-100. Refractive index was measured using Refractometer Atago RX-5000 $\alpha$ and pH was measured using $\mathrm{pH}$ meter Consort C3020.

\subsection{Method and Procedure.}

Kitolod leaves extraction was carried out by maceration method. Kitolod leaves were dried and then grinded using blender, taken as much as 250 grams then macerated using ethanol solvent for $3 \times 24$ hours. The filtrate was then separated and evaporated using a rotary evaporator until a concentrated extract was obtained.

Emulsifiable Concentrate (EC) formulation was made by mixing the two active ingredients of kitolod extract and eugenol using a magnetic stirrer. Furthermore, the surfactant combination used Tween 80 and Span 85 in several ratio with different hydrophile-lipophile balance (HLB), as shown in Table 1, which was homogenized using magnetic stirrer. All ingredients were mixed in one container to be homogenized using a magnetic stirrer with speed $1000 \mathrm{rpm}$ for 30 minutes to form oil phase. Then, the oil phase was mixed with ethanol as a 
solvent with ratio 1:5 then stirred again until homogeneously forming an EC formulation. EC formulation was added with water at a ratio of 1:10 for emulsion stability test.

Table 1. Eugenol and Kitolod Leaves Extract Fungicide Formulation.

\begin{tabular}{|c|c|c|c|c|c|}
\hline \multirow{2}{*}{ Formula } & \multicolumn{2}{|c|}{ Oil 50\% } & \multicolumn{2}{|c|}{ Surfactant $50 \%$} & \multirow{2}{*}{ HLB } \\
\hline & Eugenol & Kitolod extract & Span 85 & Tween 80 & \\
\hline A1 & $95 \%$ & $5 \%$ & $60 \%$ & $40 \%$ & 7 \\
\hline A2 & $95 \%$ & $5 \%$ & $65 \%$ & $35 \%$ & 6 \\
\hline A3 & $95 \%$ & $5 \%$ & $70 \%$ & $30 \%$ & 5 \\
\hline B1 & $96 \%$ & $4 \%$ & $60 \%$ & $40 \%$ & 7 \\
\hline $\mathrm{B} 2$ & $96 \%$ & $4 \%$ & $65 \%$ & $35 \%$ & 6 \\
\hline B3 & $96 \%$ & $4 \%$ & $70 \%$ & $30 \%$ & 5 \\
\hline $\mathrm{C} 1$ & $97 \%$ & $3 \%$ & $60 \%$ & $40 \%$ & 7 \\
\hline $\mathrm{C} 2$ & $97 \%$ & $3 \%$ & $65 \%$ & $35 \%$ & 6 \\
\hline $\mathrm{C} 3$ & $97 \%$ & $3 \%$ & $70 \%$ & $30 \%$ & 5 \\
\hline D1 & $98 \%$ & $2 \%$ & $60 \%$ & $40 \%$ & 7 \\
\hline D2 & $98 \%$ & $2 \%$ & $65 \%$ & $35 \%$ & 6 \\
\hline D3 & $98 \%$ & $2 \%$ & $70 \%$ & $30 \%$ & 5 \\
\hline E1 & $99 \%$ & $1 \%$ & $60 \%$ & $40 \%$ & 7 \\
\hline E2 & $99 \%$ & $1 \%$ & $65 \%$ & $35 \%$ & 6 \\
\hline E3 & $99 \%$ & $1 \%$ & $70 \%$ & $30 \%$ & 5 \\
\hline
\end{tabular}

The emulsion stability test was carried out using water as the dispersion phase. The test was done by observing the formation of destabilization which was recorded every 10 minutes. The formulation with no separation further characterized by particle size and polydispersity stability using particle size analyzer. The observation was conducted 3 hours with measurement intervals every 10 minutes. The selection of the optimal surfactant composition was based on the result of the most stable emulsion test.

\section{Results and Discussion}

\subsection{Eugenol and Kitolod Leaves Extract Chemical Constituent Characterization.}

Chemical constituent of Kitolod leaves extract was analyzed using GCMS and the chromatogram is shown in Figure 1 and the detailed compound detected in the extract is shown in Table 2.

The main compound of kitolod leaves is Hexanedioic acid, dioctyl ester. This compound is an aliphatic dicarboxylic acid that can be used as adhesive, plasticizer, buffering agent in food and insecticides [6].

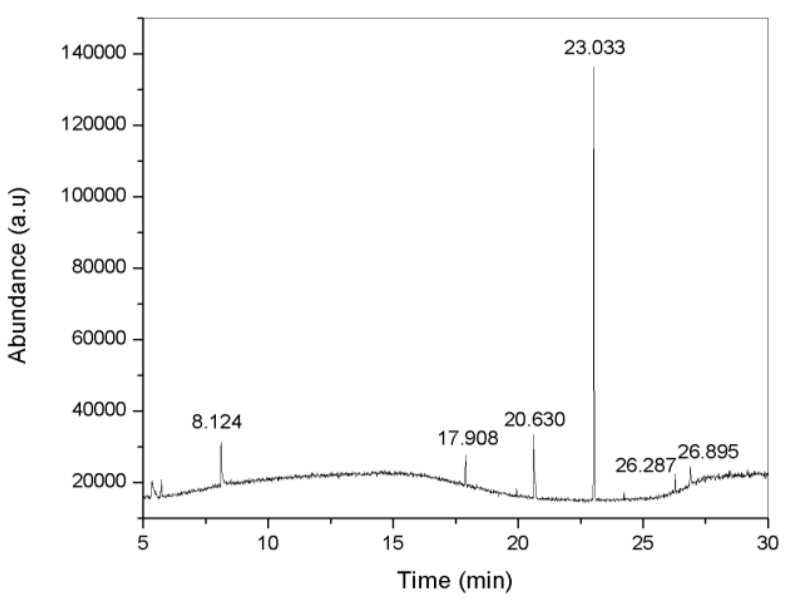

Figure 1. Kitolod Leaves Ethanolic Extract Chromatogram. 
Other compounds are acetophenone which is a methyl ketone groups that can be used as flavoring agent or adjuvant, and solvent [7]. Spirohexan-4-one, 5-chloro-6,6-dimethyl- is a phenol compound [8]. Silicic acid, diethyl bis (trime-thylsilyl) ester is ester group that also found in Piper Betle Leaves that can be used as antimicrobial agent [9].

Table 3 and Figure 2 shows GCMS analysis with pure eugenol compound at retention time 11.876 minutes. Eugenol has been widely used as biopesticides. It possesses much biological activity such as antimicrobial, antifungal and also repellent properties. The antifungal activity mostly related to phenolic group with mechanism membrane binding and permeability shift that causes plasma membrane destabilization [10].

Table 2. Chemical Constituent of Kitolod Leaves Ethanolic Extract.

\begin{tabular}{c|c|c} 
Retention Time & Name of Compound & \%Area \\
\hline 8.124 & Acetophenone & 10.01 \\
\hline 17.908 & Spirohexan-4-one, 5-chloro-6,6-dimethyl- & 3.95 \\
\hline 20.630 & Acetaldehyde & 12.44 \\
\hline 23.033 & Hexanedioic acid, dioctyl ester & 53.30 \\
\hline 26.287 & Squalene & 1.93 \\
\hline 26.895 & Silicic acid, diethyl bis (trimethylsilyl) ester & 3.55
\end{tabular}

Table 3. Chemical Constituent of Eugenol

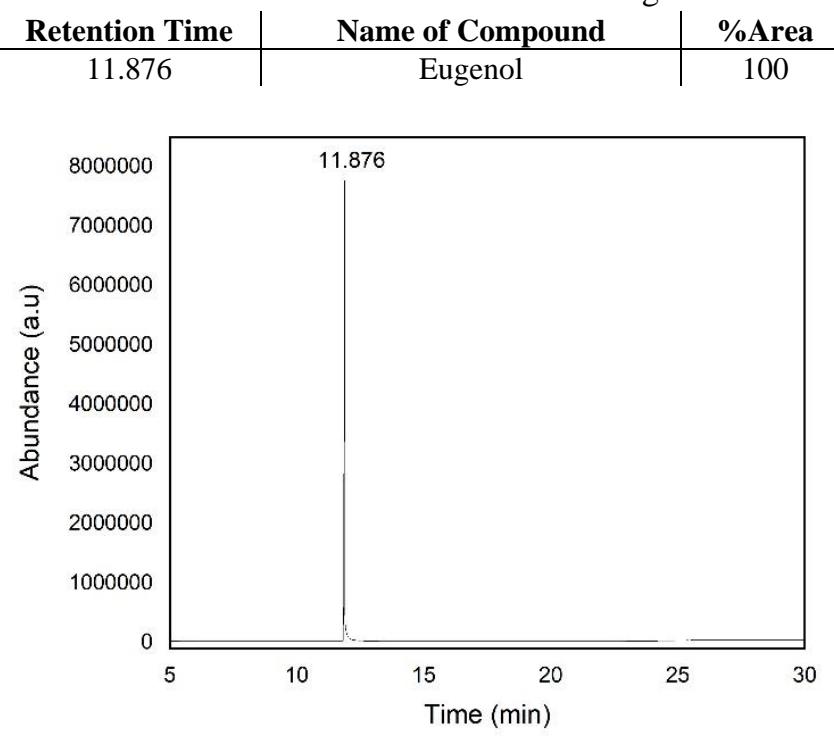

Figure 2. Eugenol chromatogram.

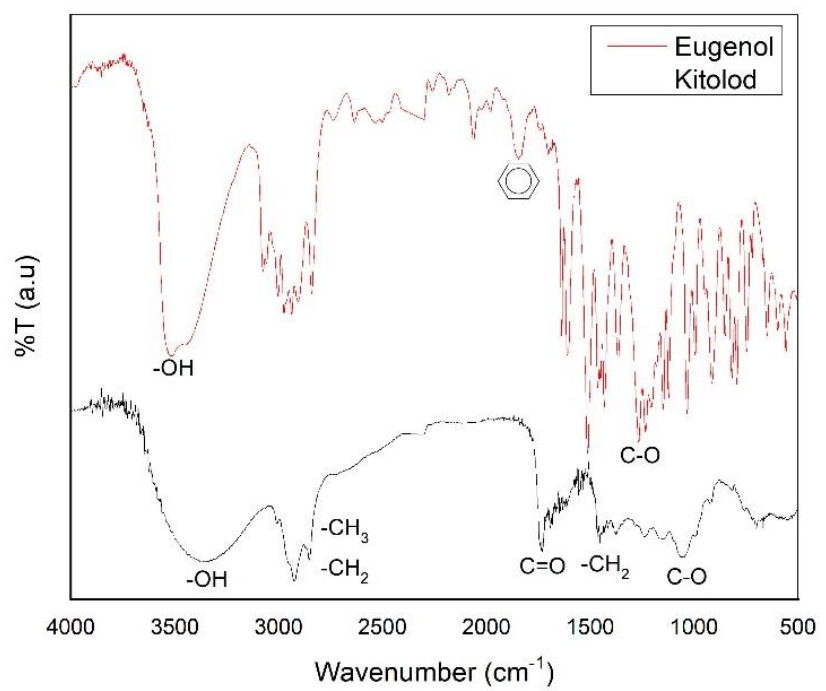

Figure 3. Eugenol and Kitolod Leaves Ethanolic Extract IR Spectra. 
The Chemical groups of eugenol and kitolod extract was analyzed using FTIR. As shown in Figure 3, Eugenol showed peaks at wavenumber $3522.02 \mathrm{~cm}^{-1}$ corresponding to -OH stretching, $2056.12 \mathrm{~cm}^{-1}$ and $1514.12 \mathrm{~cm}^{-1}$ which correspond to substituted and aromatic benzene compound, and at $1255.66 \mathrm{~cm}^{-1}$ due to C-O stretching [11]. Kitolod leaves ethanolic extract showed peak at $3360 \mathrm{~cm}^{-1}$ due to $-\mathrm{OH}$ stretching. $2926,01 \mathrm{~cm}^{-1}$ and $1450.47 \mathrm{~cm}^{-1}$ which assigned to $-\mathrm{CH}_{3}$ and $-\mathrm{CH}_{2}$ - stretching in aliphatic compound, this corresponds with GCMS result of which shows the presence of aliphatic compound. The peak at $1732.08 \mathrm{~cm}^{-1}$ corresponds to $\mathrm{C}=\mathrm{O}$ stretch in aldehyde which also occurs in GCMS result as acetaldehyde. $\mathrm{C}$ $\mathrm{O}$ stretch at $1055.06 \mathrm{~cm}^{-1}$ in primary alcohol, this can be from the trace of ethanol from the extraction method.

\subsection{Nanoemulsion Concentrate Stability Study.}

In emulsion stability test destabilization such as separation and sedimentation was recorded every ten minutes for 3 hours until 24 hours. The result is shown in Table 4.

Table 4. Emulsion Stability Test of Kitolod Leaves Extract and Eugenol EC Formulation.

\begin{tabular}{c|c|c|c|c|c|c|c|c}
\multirow{2}{*}{ Formula } & \multicolumn{10}{|c}{ Time (Min) } \\
\cline { 2 - 10 } A1 & $\mathbf{1}$ & $\mathbf{1 0}$ & $\mathbf{2 0}$ & $\mathbf{3 0}$ & $\mathbf{6 0}$ & $\mathbf{1 2 0}$ & $\mathbf{1 8 0}$ & $\mathbf{2 4 h}$ \\
\hline A2 & - & $\circ$ & $\circ$ & $\circ$ & $\circ$ & $\circ$ & $\circ$ & $\Delta$ \\
\hline A3 & - & $\circ$ & $\circ$ & $\circ$ & $\circ$ & $\circ$ & $\circ$ & $\Delta$ \\
\hline B1 & - & - & $\circ$ & $\circ$ & $\circ$ & $\circ$ & $\circ$ & $\Delta$ \\
\hline B2 & - & $\circ$ & $\circ$ & $\circ$ & $\circ$ & $\circ$ & $\circ$ & $\Delta$ \\
\hline B3 & - & $\circ$ & $\Delta$ & $\Delta$ & $\Delta$ & $\Delta$ & $\Delta$ & $\Delta$ \\
\hline C1 & - & $\circ$ & $\circ$ & $\circ$ & $\circ$ & $\Delta$ & $\Delta$ & $\Delta$ \\
\hline C2 & - & - & - & $\Delta$ & $\Delta$ & $\Delta$ & $\Delta$ & $\Delta$ \\
\hline C3 & - & $\circ$ & $\circ$ & $\Delta$ & $\Delta$ & $\Delta$ & $\Delta$ & $\Delta$ \\
\hline D1 & - & $\circ$ & $\circ$ & $\circ$ & $\Delta$ & $\Delta$ & $\Delta$ & $\Delta$ \\
\hline D2 & - & $\circ$ & $\circ$ & $\circ$ & $\Delta$ & $\Delta$ & $\Delta$ & $\Delta$ \\
\hline D3 & - & $\circ$ & $\circ$ & $\circ$ & $\circ$ & $\Delta$ & $\Delta$ & $\Delta$ \\
\hline E1 & - & - & - & - & - & - & - & - \\
\hline E2 & - & - & - & - & - & - & - & - \\
\hline E3 & - & - & - & - & - & - & - & - \\
- No Destabilization & $\circ$ Oil separation $\Delta$ Sedimentation
\end{tabular}

It is seen that formula A1, A2 and A3 showed similar behavior. There was no separation or sedimentation on minute 1 , but it started to form an oil droplet on the upper layer of emulsion from minute 10 and after 24 hours the green colored sedimentation was formed on the bottom of test tube. Phase separation occurred because of oil and water density differences. The oil droplets were formed because of the gravitational separation due to changes in average droplet size overtime through oil droplets aggregation [12].

Formula B, C and D showed similar behavior. All formulation showed no sedimentation on minute 1 but gradually showed oil separation starts from minute 10 . Sedimentation started to from in minutes 20 . Oil should have a great solubilizing property to acquire maximum active agent loading and to ease stable nanoemulsion formation [13]. The occurrence of sedimentation can be caused by the lack of kitolod extract solubility in eugenol in the concentration of kitolod extract more than $1 \%$.

Formula E showed the best stability with no sedimentation and separation. Emulsion formed from a stable mixture of oil, water, surfactant and co-surfactant. Surfactant used in this formulation is Span 85 with HLB 1.8 and Tween 80 with HLB 15. A combination of low and high surfactant relatively more effective to modify the HLB system and form stable nanoemulsion compared with single surfactant. Surfactants with HLB value less than 10 are 
hydrophobic where it can enhance the entrapment of active agent. Tween 80 is hydrophilic and acted as co-surfactant which reduces oil/water interface and initiates the spontaneous nanoemulsion formation [13]. The composition of eugenol in this formulation is $99 \%$ and kitolod extract is $1 \%$. The low composition of kitolod produces more homogenous oil phase due to kitolod solubility in eugenol thus improve the stability of the system.

The surfactant combination HLB value ranged from 5-7 corresponded to HLB eugenol which is 6. Surfactant mixture's HLB value must be close to oil phase HLB value to make emulsion formulation [14]. The homogenous oil phase and the required HLB value could produce stable nanoemulsion system.

\subsection{Nanoemulsion Particle Size and Polydispersity Index Stability.}

Formula E was measured its particle size and polydispersity index for 6 hours every 10 minutes as shown in Figure 4 and 5 .

The result of particle size observation is shown in Figure 4 and Table 5. Particle size Formula E1 was around $280 \mathrm{~nm}$ with a narrow particle size range for every measurement. It is also shown as standard deviation and relative standard deviation (RSD) in Table 5 . Formula E2 had particle size around $400 \mathrm{~nm}$ with wide range particle size for 6 hours observation, while Formula E3 particle size was similar to Formula E1 but the range was wider.

Span 85 has three hydrophobic branches and one hydroxyl group can conduct interaction via hydrogen bonding with eugenol through the interaction of $\mathrm{O}$ and $\mathrm{H}$ atom. The type of this structure tends to destabilize at low concentration. In this study the concentration of Span 85 was relatively high which can conduct high stability for oil in water $(\mathrm{o} / \mathrm{w})$ emulsion type [15]. Tween 80 is the type of nonionic surfactant which is an ethoxylated sorbitan with oleic acid tail. The combination of low HLB from Span 85 and inter-droplet steric repulsion from Tween 80 form high oil dispersion and stable o/w emulsions due to low interfacial tension [16].

Ethanol was used in this study because it can dissolve both kitolod extract and eugenol and also as co-surfactant to improve dissolve ability and effectiveness at dispersing oil phase in o/w emulsions [17].

Formula E1 with surfactant ratio Span 85: Tween 80 60:40 produced small particle size with a narrow standard deviation for 6 hours represent stable emulsions behavior. This was similar to Wiyani, et al, where the best mixed surfactant Span 80 and Tween 80 is 60:40 [18]. The narrow standard deviation of droplet size with combination surfactant Span 85/Tween 80 also shown in Yang et al o/w nanoemulsion formulation. It is related to HLB value that the higher value provides small droplet size [19]. The nanosized droplet was produced because surfactant molecule has sufficient concentration to migrate from the oil phase to the aqueous phase of the emulsion. Surfactant prevents droplets merge with each other because the rate of surfactant adsorption in interfacial layer is greater than the droplet collide velocity so that it forms small and uniform droplets [20]. Polydispersity index (PDI) also known as heterogeneity index define the degree of non-uniformity of droplet size distribution. A sample with PDI values greater than 0.7 is said polydisperesed where it has broad droplet size distribution [21].

The PDI of Formula E is shown in Table 6 and Figure 5. Generally, all formula had PDI below 0.7 which represent narrow droplet size distribution and there was no significant difference in all formulation. Formula E1 had smaller PDI with lower standard deviation and RSD compared with Formula E2 and E3. PDI is influenced by the kinetics of surface adsorption of the surfactant [22]. In Formula E the composition of oil phase and surfactant Span 85/Tween 
80 conduct maximum soluble system that allows droplets dispersed evenly in the continuous phase [23].

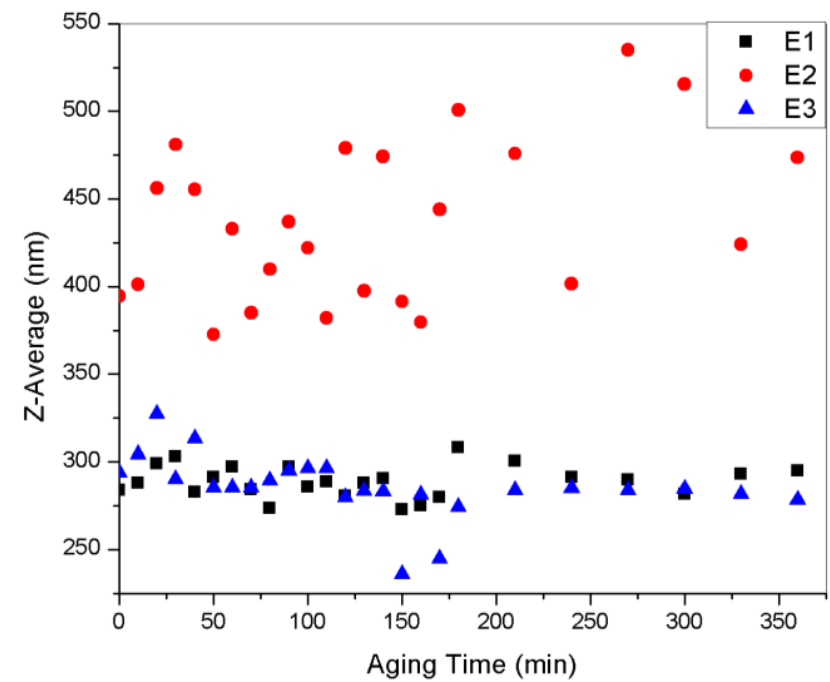

Figure 4. Particle Size Distribution of Formula E by 6 Hours Aging Time.

Table 5. Average Particle Size Diameter of Formula E

\begin{tabular}{c|c|c|c|}
\hline & E1 & E2 & E3 \\
\hline Avrg. Diameter (nm) & $288.7 \pm 9.2$ & $404 \pm 46$ & $285 \pm 17.9$ \\
\hline RSD (\%) & 3.2 & 11.4 & 6.3 \\
\hline
\end{tabular}

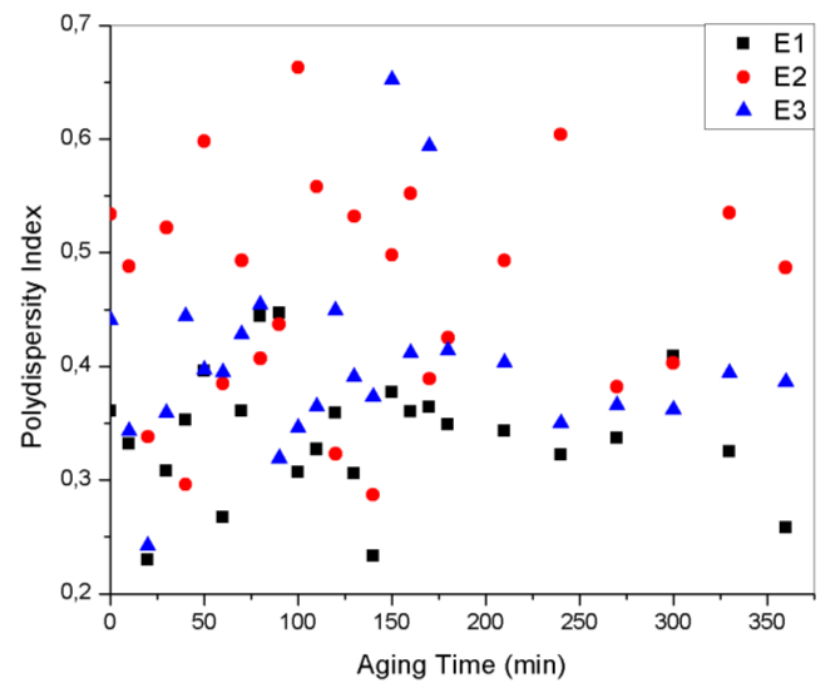

Figure 5. Polydispersity Index of Formula E by 6 Hours Aging Time.

Table 6 . Average Polydispersity Index of Formula E.

\begin{tabular}{c|c|c|c} 
& E1 & E2 & E3 \\
\hline Avrg. PDI & $0.339 \pm 0.055$ & $0.465 \pm 0.1$ & $0.403 \pm 0.081$ \\
\hline RSD (\%) & 16.3 & 21.4 & 20.1
\end{tabular}

\subsection{Nanoemulsion Physical Characterization.}

The Refractive index describes the transparency and isotropic nature of nanoemulsion. It is determined by using refractometer and its value is compared with refractive index of water which is 1.333. If the refractive index value of the sample similar to refractive index of water, the nanoemulsion sample is considered to have transparent properties [24]. Table 7 shows the refractive index of Formula E1, E2 and E3 and the value close to refractive index of water. This showed that the fungicide has uniform nanoemulsion structure correspond to isotropic and 
stable emulsion [25]. This also supported by the stability test and PDI value under 0.7 as shown in the table above.

$\mathrm{pH}$ value of the formulation is shown in Table 7 . Morsi et al reported that the $\mathrm{pH}$ in the range 4.9-5.5 is acceptable and non-irritant for eye [24]. The $\mathrm{pH}$ value in this study was ranged between 6-7 and it is still in neutral $\mathrm{pH}$ range and considered safe for field application.

Table 7. Refractive Index and $\mathrm{pH}$ of Formula E by 6 Hours Aging Time.

\begin{tabular}{c|c|c|c} 
Formula & \multicolumn{2}{|c|}{ Refractive Index } & \multirow{2}{*}{ pH } \\
\hline & Minute -0 & Minute-360 & \\
\hline E1 & 1.33821 & 1.33835 & 7.3 \\
\hline E2 & 1.33802 & 1.33796 & 6.5 \\
\hline E3 & 1.33908 & 1.33725 & 7.0
\end{tabular}

\section{Conclusions}

Eugenol and kitolod leaves extract has potential for pesticide because it possesses antimicrobial compound namely hexanedioic acid and silicic acid and can be formulated in emulsified concentrate (EC) formulation. Formula E1 is the most stable EC formulation for 6 hours observation with concentration eugenol 99\%, kitolod extract 1\%, Span $8560 \%$ and Tween $8040 \%$, with oil/surfactant ratio 50/50 and ethanol as solvent by ratio 1:5. The average droplet size of formula E1 was $288.7 \pm 9.2 \mathrm{~nm}$ with monodisperse distribution by average PDI 0.339. This finding widened the knowledge of optimization based on HLB value and types of surfactant that can produced nano sized droplet with a simple procedure through spontaneous emulsification. Further, it can be applied in the field as botanical pesticide which is safer for the environment. The nano sized droplet is expected can enhance the efficacy effectiveness and also stability during the application.

\section{Funding}

Insentif Riset Sistem Inovasi Nasional (Insinas) Project, SK No.4/E/KPT/2019, Ministries of Research, Technology and Higher Education (Kemenristekdikti), Indonesia.

\section{Acknowledgments}

The author would like to thank Ministries of Research, Technology and Higher Education (Kemenristekdikti) for funding this research through Insentif Riset Sistem Inovasi Nasional (Insinas) Project, SK No.4/E/KPT/2019 and Research Center for Chemistry, Indonesian Institute of Sciences (LIPI) for supporting laboratory testing and analysis.

\section{Conflicts of Interest}

The authors declare no conflict of interest.

\section{References}

1. Lengai, G.M.W.; Muthomi, J.W.; Mbega, E.R. Phytochemical Activity and Role of Botanical Pesticides in Pest Management for Sustainable Agricultural Crop Production. Sci. African 2020, 7, 1-13, https://doi.org/10.1016/j.sciaf.2019.e00239.

2. Arfiandi, A.; Zulfisa, Z.; Ramdhani, I.; Makhfirrs, U.; Marjoni, M.R. Growth Inhibition Test of Streptococcus Mutans against Methanol Extract / Fractions of Kitolod ( Isotoma Longiflora ( L.) C . Presl.). Int. J. Res. Pharm. Pharm. Sci. 2018, 3, 16-18.

3. Mak, K.; Kamal, M.B.; Ayuba, S.B.; Sakirolla, R.; Kang, Y.; Mohandas, K.; Balijepalli, M. =K.; Ahmad, S. H.; Pichika, M.R. A Comprehensive Review on Eugenol' $\mathrm{s}$ Antimicrobial Properties and Industry Applications: A Transformation from Ethnomedicine to Industry. Pharmacogn. Rev 2019, 13, 1-9, 
http://dx.doi.org/10.4103/phrev.phrev_46_18.

4. Hazra, D.K.; Purkait, A. Role of Pesticide Formulations for Sustainable Crop Protection and Environment Management : A Review. J. Pharmacogn. Phytovhemistry 2019, 8, 686-693, https://doi.org/10.22271/phyto.

5. McClements, D.; Decker, E.; Weiss, J. Emulsion-Based Delivery Systems for Lipophilic Bioactive Components. J. Food Sci. 2007, 72, 109-124, https://doi.org/10.1111/j.1750-3841.2007.00507.x.

6. Musser, M.T. Adipic Acid. In: Ullmann's Encyclopedia of Industrial Chemistry. Wiley-VCH Verlag GmbH \& Co. KGaA: Weinheim, 2000; pp. 1-10.

7. FDA. Food and Drug Administration, Acetophenone. Silver Spring, 2020.

8. Shawal, N.N.; Musa, A.M.; Kamar, S.; Nurhidayah, A.; Yee, S.T.; Dadum, H.U.; Jibril, M.; Husna, M.Z. Hydrophobic-Synthesis of Bio-Based Epoxy Substrate Using Methyl Ester and Its Dust Deposition and Decontamination Effects. Adv. Mater. Reserach 2014, 1043, 76-80, https://doi.org/10.4028/www.scientific.net/AMR.1043.76.

9. Foo, L.W.; Salleh, E.; Hana, S.N. Green Extraction of Antimicrobial Bioactive Compound from Piper Betle Leaves : Probe Type Ultrasound-Assisted Extraction vs Supercritical Carbon Dioxide Extraction. Chem. Eng. Trans. 2017, 56, 109-114, https://doi.org/10.3303/CET1756019.

10. Olea, F.; Bravo, A.; Mart, R.; Thomas, M.; Sedan, C.; Espinoza, L.; Zambrano, E.; Carvajal, D. Silvamoreno, E.; Carrasco, H. Antifungal Activity of Eugenol Derivatives against Botrytis Cinerea. Molecules 2019, 24, 1-14, https://doi.org/10.3390/molecules24071239.

11. Peng, S.; Zou, L.; Liu, W.; Gan, L.; Liang, R.; Liu, C.; Niu, J.; Cao, Y.; Liu, Z.; Chen, X. Storage Stability and Antibacterial Activity of Eugenol Nanoliposomes Prepared by an Ethanol Injection - Dynamic HighPressure Microfluidization Method. J. Food Prot. 2015, 78, 22-30, https://doi.org/10.4315/0362-028X.JFP14-246.

12. Mollakhalili Meybodi, N.; Mohammadifar, M.A.; Naseri, A.R. Effective Factors on the Stability of Oil-inWater Emulsion Based Beverage: A Review. J. Food Qual. Hazards Control 2014, 1, 67-71.

13. Amin, N.; Das, B. A Review on Formulation and Characterization of Nanoemulsion. Int. J. Curr. Pharm. Res. 2019, 11, 42-46, https://doi.org/10.22159/ijcpr.2019v11i4.34925.

14. Agrendo, P.; Rave, M.C.; Echeverri, J.D.; Romero, D.; Salamanca, C.H. An Evaluation of the Physicochemical Properties of Stabilized Oil-In-Water Emulsions Using Different Cationic Surfactant Blends for Potential Use in the Cosmetic Industry. Cosmetics 2019, 6, 1-12, https://doi.org/10.3390/cosmetics6010012.

15. Martins, E.; Renard, D.; Adiwijaya, Z.; Karaoglan, E. Oil Encapsulation in Core - Shell Alginate Capsules by Inverse Gelation. I : Dripping Methodology. J. Microencapsul. 2017, 34, 82-90, https://doi.org/10.1080/02652048.2017.1284278.

16. Rocchio, J.; Neilsen, J.; Everett, K.; Bothun, D. A Solvent-Free Lecithin-Tween 80 System for Oil Dispersion. Colloids Surf. A 2018, 533, 218-223, https://doi.org/10.1016/j.colsurfa.2017.08.038.

17. Elfiyani, R.; Amalia, A.; Pratama, S.Y. Effect of Using the Combination of Tween 80 and Ethanol on the Forming and Physical Stability of Microemulsion of Eucalyptus Oil as Antibacterial. J. Young Pharm. 2017, 9, S1-S4, https://doi.org/10.5530/jyp.2017.1s.1.

18. Wiyani, L.; Aladin, A.; Yani, S. Stability Of Virgin Coconut Oil Emulsion With Mixed Emulsifiers Tween 80 And Span 80. ARPN J. Eng. Appl. Sci. 2016, 11, 5198-5202.

19. Yang, C.Y.; Key, S.; Resources, U.S.A.; Pierce, F.; Agriculture, F. Characterization and Antibacterial Activity of Oil-In-Water Nano-Emulsion Formulation Against Candidatus Liberibacter Asiaticus. Plant Dis. 2016, 100, 2448-2454, https://doi.org/10.1094/PDIS-05-16-0600-RE.

20. Costa, C.; Medronho, B.; Filipe, A.; Mira, I.; Lindman, B.; Edlund, H.; Norgren, M. Emulsion Formation and Stabilization by Biomolecules: The Leading Role of Cellulose. Polymers (Basel) 2019, 11, 1-18, https://doi.org/10.3390/polym11101570.

21. Danaei, M.; Dehghankhold, M.; Ataei, S.; Davarani, F.H.; Javanmard, R.; Dokhani, A.; Khorasani, S.; Id, M. R.M. Impact of Particle Size and Polydispersity Index on the Clinical Applications of Lipidic Nanocarrier Systems. Pharmaceutics 2018, 10, 1-17, https://doi.org/10.3390/pharmaceutics10020057.

22. Silva, H.D.; Cerqueira, M.A.; Vicente, A.A. Influence of Surfactant and Processing Conditions in the Stability of Oil-in-Water Nanoemulsions. J. Food Eng. 2015, 167, 89-98, https://doi.org/10.1016/j.jfoodeng.2015.07.037.

23. Polychniatou, V.; Tzia, C. Study of Formulation and Stability of Co-Surfactant Free Water-in-Olive Oil Nano- and Submicron Emulsions with Food Grade Non-Ionic Surfactants. J. Am. Oil Chem. 2014, 91, 7988, https://doi.org/10.1007/s11746-013-2356-3.

24. Gurpreet, K.; Singh, S.K. Review of Nanoemulsion Formulation and Characterization Techniques. Indian J. Pharm. Sci. 2018, 80, 781-789, https://doi.org/10.4172/pharmaceutical-sciences.1000422.

25. Kotta, S.; Khan, A.W.; Ansari, S.H.; Sharma, R.K.; Ali, J. Formulation of Nanoemulsion : A Comparison between Phase Inversion Composition Method and High-Pressure Homogenization Method Formulation of Nanoemulsion: A Comparison between Phase Inversion Composition Method and High-Pressure Homogenization Method. Drug Deliv. 2015, 22, 455-466, https://doi.org/10.3109/10717544.2013.866992. 